\title{
Scaffolding Interactions With Preschool Children: Comparisons Between Chinese Mothers and Teachers Across Different Tasks
}

\author{
Jin Sun and Nirmala Rao The University of Hong Kong
}

\begin{abstract}
This study investigated how Chinese adults adjusted their scaffolding in interactions with children during problem-solving tasks. Fifty-seven 5-year-olds (from low and high socioeconomic status [SES] backgrounds) completed a playlike task (puzzle) and a school-like task (worksheet) with their mothers and teachers, respectively. Adult-child interactions were videotaped, and the analyses focused on how adults adjusted their scaffolding as a function of children's responses. Results indicated that teachers adjusted their scaffolding more appropriately than mothers, and that adults' sensitivity to children's understanding was associated with more appropriate scaffolding. Children from middle or upper SES families received more optimal scaffolding than those from lower SES families, and both mothers and teachers provided more skilled scaffolding in the school-like task than in the playlike task. Findings suggest that family SES, adults' professional training, and task characteristics, as well as adults' understanding of children's mastery, should be considered in the analysis of dyadic problem solving.
\end{abstract}

Children's problem-solving ability is facilitated through interactions with adults, but there is a dearth of research that has examined specific interaction processes in adult-child dyads during problem solving. This study focused on how Chinese mothers and teachers adjusted their scaffolding as a function of children's responses in different problem-solving tasks. It

Jin Sun and Nirmala Rao, Faculty of Education.

This article is based on research conducted by the first author, in partial fulfillment of a doctorate, under the supervision of the second author. The research was supported by a grant from the Sik Sik Yuen Educational Fund and the Faculty of Education Research Fund of The University of Hong Kong. We thank the participants, as well as Raymond Lam for his assistance with statistical analyses.

Address correspondence to Jin Sun, Faculty of Education, The University of Hong Kong, Hong Kong. Phone: (852) 2219-4867. E-mail: sunjin16@hku.hk.

Merrill-Palmer Quarterly, January 2012, Vol. 58, No. 1, pp. 110-140. Copyright (C) 2012 by Wayne State University Press, Detroit, MI 48201. 
also considered the influences of children's family background on the scaffolding they received.

\section{The Dynamic Nature of Scaffolding}

Scaffolding is an interactive process that helps a child to gradually master the skills to solve problems that are beyond his or her current capability and ensures that the child not only completes the task but gradually acquires the skills to complete the task independently (Wood, Bruner, \& Ross, 1976; Wood $\&$ Middleton, 1975). The reciprocity between the adult and the child is of vital importance in dyadic interactions as the adult has to gauge accurately and react to the child's responses appropriately (Langry, Garner, Swank, \& Baldwin, 1996). For example, research indicates that mothers' instructions become less explicit, less concrete, and more verbal as infants gain mastery (Heckhausen, 1987). Mothers shorten sentences and simplify scaffolding contents when children encounter difficulties, but offer more complex suggestions as children progress toward solving a problem (Mast, 2002). Furthermore, mothers provide higher levels of scaffolding or maintain the level of their instruction in response to children's compliance (Gauvain \& Perez, 2008).

Adults' sensitivity to children's developing capabilities is reflected in the application of the contingent shift rule (CSR; Wood et al., 1976). Adults provide more support following a child's failure and less support following success, and this is an important feature of effective scaffolding (Conner \& Cross, 2003). However, existing research has not specifically focused on how adults adjust the information delivered (scaffolding content) and the way information is transferred to the child (scaffolding manner) during the dyadic interaction.

Moreover, previous studies that have examined the dynamic nature of scaffolding have focused mainly on adults' adjustment of their scaffolding behaviors after one specific response from a child, and this may be insufficient to judge whether adults have adjusted their scaffolding appropriately. Adults may make adjustments only when they are sure that a change in their scaffolding is needed, and adjustments may be made after two or more similar responses by a child. Therefore, analyses of an adult's adjustment of scaffolding behaviors not only after a single response by a child but after two similar and consecutive responses enable a more comprehensive understanding of the dynamic process in adult-child problem solving.

\section{Variations in Scaffolding Across Partners and Tasks}

Partner influences. Mothers and teachers have important influences on a child's early development, but they differ in the type of scaffolding 
they provide for young children. Teachers are better than mothers at simplifying a task into manageable components, encouraging the child's active involvement in problem solving, transferring the responsibility gradually to the child, and demonstrating how to solve a problem (Hess, Dickson, Price, \& Leong, 1979; Wertsch, Minick, \& Arns, 1984).

Family background is also related to mothers' instructional behaviors in dyadic problem-solving tasks with their children. Mothers from high socioeconomic status (SES) backgrounds are more skillful in helping children complete the collaborative activity than those from low SES families. The former use higher-level instruction, offer more strategic suggestions, ask more open-ended questions, and provide more opportunities for exploration than other mothers (Hoff, Laursen, \& Tardif, 2002; Leseman \& Sijsling, 1996; Zegiob \& Forehand, 1975). However, it should be noted that results from some studies suggest that SES background does not fundamentally change the pattern of mother-child interactions, but alters the quantity of certain behaviors (Farran \& Haskins, 1980).

Task influences. The characteristics of different tasks also influence adults' scaffolding. For instance, parents tend to assume more responsibility, provide more commands, and use more nonverbal physical prompts as the structure and complexity of tasks increase (Freund, 1990; Gonzalez, 1996; Harris, Terrel, \& Allen, 1999). Mothers are also more inclined to promote children's independence and to be more responsive to children's interest in homelike tasks compared to school-like tasks (Kermani \& Janes, 1999). Adults' adjustment of scaffolding in various tasks might reflect differences in their interpretation of the tasks (Rogoff, 1990). More elaborate and facilitating strategies are provided in activities that are perceived as learning opportunities for children and in which adult support is considered necessary. Furthermore, cultural background and beliefs may be related to adults' interpretation of and involvement in specific problem-solving tasks (Gonzalez, 1996; Neitzel \& Stright, 2004).

In summary, previous studies have shown that scaffolding varies across partners and problem-solving tasks. However, the influences of partner and task traits on adults' reactions to the child's initial responses have been neglected; therefore, the present study explicitly considered mothers' and teachers' reactions to children's responses across different tasks.

\section{Parenting and Early Childhood Education in the Chinese Context}

Although Chinese parents are more authoritarian and restrictive than their Euro-American counterparts (Chiu, 1987; Lin \& Fu, 1990), they facilitate children's performance by intertwining authoritarian and authoritative 
parenting in given situations (Xu et al., 2005). They are more concerned about children's compliance with adult authority (W. T. Liu, 1986) but express warmth in more subtle ways by being supportive and sensitive to children's needs (Chao, 1994). Children's school achievement is highly stressed even in the early years (Pang \& Richey, 2007; Rao, McHale, \& Pearson, 2003).

Since the 1980s, mainland China has experienced considerable industrialization and Westernization. Western ideology and Chinese traditional values have been integrated into parenting practices (M. Liu et al., 2005; Xu et al., 2005). Chinese parents who have some knowledge about Western child-rearing beliefs and practices are less inclined to use power assertion and are more likely to use inductive reasoning in their interaction with children than are parents who have not been exposed to these progressive ideas (Parke, 2004; Xu et al., 2005).

China's early childhood education is also influenced by both traditional Chinese and Western ideas. Traditional Chinese teaching and learning emphasize training, knowledge acquisition through memorization, and the efforts of the child, teacher authority, and discipline (Rao et al., 2003). Traditional preschool education in China is thus teacher centered and academically oriented (Pang \& Richey, 2007). At the same time, Western educational beliefs, such as respecting children, using active learning and teaching methods, and learning through play have been gradually accepted and promoted in Chinese preschools since the initiation of kindergarten educational reform in the 1980s (Y. Liu \& Feng, 2005).

Against this background, the present study examined how Chinese mothers and teachers provided scaffolding for preschoolers as a function of the child's responses in two basically different problem-solving tasks; the influences of the family SES status on the scaffolding that children received was also considered. Comparing the scaffolding of mothers and teachers is fundamental to understand adults' scaffolding in authentic educational situations and how both adult and task characteristics influence scaffolding patterns and processes. Such information can enrich our knowledge of scaffolding. Although previous studies have demonstrated task and partner effects on adults' scaffolding behaviors, rarely has research integrated the examination of partners' and tasks' effects in one study, and few studies have examined those effects on the dynamic scaffolding processes. Furthermore, unlike previous work, this study focused on adults' scaffolding adjustment after both one specific and two similar and consecutive responses. We believe these measures can provide a more comprehensive and accurate understanding of scaffolding processes. In addition, there has been no empirical research systematically examining 
adults' scaffolding behaviors in different types of dyadic problem-solving tasks in the Chinese context. Comparisons with existing research may enable a better understanding of the universal and culture-specific aspects of scaffolding and the relationship between adult scaffolding and specific cultural scripts. We made the following predictions: (a) Teachers would adjust their scaffolding behaviors as a function of children's responses more appropriately than mothers, because teachers had received professional training in early childhood education, but mothers had not. (b) Mothers from the lower SES group would be less skilled in providing appropriate scaffolding in response to children's different behaviors than those from middle or upper SES backgrounds. Children from different SES backgrounds were expected to receive similar scaffolding strategies from their teachers, since all teachers had a professional qualification specifically to promote children's learning and were considered to have mastered the basic skills in appropriate scaffolding. (c) Adults would show more optimal adjustment of scaffolding as a function of children's responses in the school-like task than in the playlike task because of the emphasis on school achievement in the Chinese context. (d) After children had executed two consecutive similar responses, adults were more likely to adjust their scaffolding appropriately than after just one specific response, because children's repeated responses might serve as feedback on the effectiveness of their previous scaffolding and remind adults to adopt more appropriate scaffolding strategies thereafter.

\section{Method}

\section{Pilot Study}

A pilot study was conducted to refine the tasks and the coding framework. Ten children in an upper kindergarten class (K3) (including five girls), their mothers, and their teachers in Beijing participated in the pilot study. Six children were from middle or upper SES families. Each child solved four tasks - supermarket, jigsaw puzzle, worksheet, and map — with his or her mother and teacher, respectively. The order of tasks for mother-child and teacher-child dyads was counterbalanced by ensuring that each task occurred in each position of the task sequence at least twice. All problemsolving episodes were videotaped and coded based on adults' scaffolding manner, content, level, and children's responses. No effects of task sequence on either adults' scaffolding or children's responses were found. Mothers and teachers were interviewed after the problem solving. Based on these interviews and our observations, we adjusted the coding framework 
by combining or deleting some codes and reduced the task difficulty to ensure the tasks were within K3 children's zones of proximal development (ZPDs; Vygotsky, 1978).

\section{Participants}

A total of $65 \mathrm{~K} 3$ children enrolled in seven kindergartens in Beijing and their mothers and teachers participated in this study. The data obtained from eight children were excluded from the analyses because of their failure to complete both mother-child and teacher-child sessions. Thus, data analyses focused on 57 children ( 29 girls) who worked on the problems with both their mothers and teachers.

A total of 28 children (16 girls) were from three kindergartens that had been established by individuals or communities and catered mainly to children of migrant laborers in Beijing. Three teachers in these kindergartens took part in this study. According to ratings from the Kindergarten Banding Regulations and Rules in Beijing (Beijing Educational Committee, 2000), these kindergartens were of low quality, with limited resources and space. All of these children had lived with their parents in Beijing for at least 1 year (range $=1-3$ years). Most of these families were from rural areas of China and were engaged in physical labor or had small-scale businesses in Beijing. The mothers reported demographic information, including the child's age, family's monthly income, parents' careers, ages, and educational levels. The mean reported monthly income was $¥ 2,892.86$ per month (range $=¥ 1,500-¥ 5,500$ ), which was lower than the mean income level in Beijing in November 2006, which was $¥ 3,008.08$ per month (National Bureau of Statistics of China, 2007). None of these mothers had studied beyond Grade 8 . Since they were temporary residents in Beijing, they could not benefit from the allowance and insurance available to other Beijing residents, and their children could not be enrolled in kindergartens or primary schools for local Beijing children. They were regarded as mothers from a lower SES background in this study.

The other 29 children (including 15 girls) were born in Beijing and were enrolled in four kindergartens affiliated with a college or the government. These kindergartens recruited mainly children of staff in a specific college or government department and were of average quality, with good resources and space, according to the Kindergarten Banding Regulations and Rules in Beijing (Beijing Educational Committee, 2000). All the mothers who had children enrolled in these kindergartens had received a university education or more. Their professions included teacher, accountant, doctor, and secretary. The mean reported monthly income of these families 
was $¥ 7,206.90$ per month (range $=¥ 3,500-¥ 12,000$ ), which was much higher than the mean income level in Beijing in November 2006. These children were considered as being from middle or upper SES backgrounds. Seven teachers from this type of kindergartens participated in the teacherchild problem-solving sessions.

Children's mean age was 5.4 years (range $=4.7-6.4$ years). Mean ages for mothers and teachers were 31.8 years (range $=21.0-43.0$ years) and 24.7 years (range $=20.0-38.0$ years), respectively. There were no differences in either mothers' or teachers' ages between the two SES groups. All 10 teachers were professionally qualified to teach in preschools.

\section{Problem-Solving Tasks}

The problem-solving tasks examined in this report were selected from a larger study by the authors. Four problem-solving tasks were included in the original study. The design of the tasks was based on (a) the research purposes, (b) tasks described in the literature, (c) the literature on Chinese children's mathematical development, (d) interviews with preschool teachers, and (e) findings from the pilot study.

This article focuses on two problem-solving tasks: a jigsaw puzzle and a mathematical worksheet. Completing jigsaw puzzles is an age-appropriate task for preschoolers and is regularly used in scaffolding studies. As puzzles do not contain explicit learning information, they are considered a play task by most Chinese teachers and parents. The mathematical worksheet task is a typical learning task in primary school. Although the puzzle and worksheet tasks differed in their cognitive requirement (visual search for the puzzle task vs. number cognition for the worksheet task), the contrast of the playlikeness and school-likeness was the most distinctive and essential difference conceptualized by the adults (as mentioned by the adults in the pilot study). Therefore, we considered these two tasks to be representative of playlike and school-like activities that Chinese children were familiar with and engaged in frequently.

In the jigsaw puzzle task, each adult-child dyad was given a 20-piece puzzle and asked to put it together to match a sample picture. The shapes and positions of the pieces were exactly the same for mother-child and teacherchild interactions, although the figures depicted on the puzzles were different. In the worksheet task, the dyads had to solve an arithmetic problem on a worksheet, with " $23-9=$ ?" for mother-child dyads and " $22-8=$ ?" for teacher-child dyads. Beans, pencils, and paper were provided as aids.

Based on our pilot study, observations, and interviews with teachers and parents, we assumed that the two tasks would be within Chinese 
5-year-olds' ZPDs. These K3 children could not solve the problems independently but could complete these tasks with the help of skilled others. In the puzzle task, they could find the exact pieces at the corners and borders of the puzzles themselves, but adults' help was needed in finding the correct pieces for other positions. Chinese preschool children are familiar with mathematical worksheets, and parents commonly involve preschoolers in worksheet exercises at home. Teachers also provide formal mathematical knowledge in preschool to prepare children for primary school. According to the Regulations for the Implementation of Guidelines for Kindergartens in Beijing (tentative) (Beijing Educational Committee, 2006), most K3 children should be able to add and subtract with quantities less than 10 without adult help. Our classroom observations also suggested that many K3 Chinese children could even solve addition or subtraction problems within the quantity of 20 . We therefore believed that our worksheet task was beyond the current capability of the K 3 children, but that they could complete the task with the help of adults. As the worksheet task was considered difficult for $\mathrm{K} 3$ children, beans, pencils, and paper were provided as teaching aids.

\section{Procedure}

Letters inviting participation in this research were sent to the mothers of 35 boys and 35 girls randomly selected from the seven kindergartens; $92.3 \%$ of the mothers gave written consent for their children to participate.

All adult-child problem-solving sessions were conducted in classrooms in the children's kindergartens. The classrooms were equipped with a desk, two chairs, materials for the tasks, and a video camera. The adult-child dyads were asked to solve four problem tasks in a fixed sequence-supermarket, puzzle, worksheet, and map—because no task sequence effects on mother-child and teacher-child interactions had been found in the pilot study. A total of 28 randomly selected children worked with their mothers first.

The child was given time to become familiar with the video camera before the formal problem-solving procedure. Each task lasted for less than $20 \mathrm{~min}$. If the dyads did not complete the task within $20 \mathrm{~min}$, the researcher stopped the task and continued with the next one. All adult-child dyads, except for one mother-child dyad that exceeded $20 \mathrm{~min}$ in the puzzle task, completed both tasks within 20 min.

All mother-child and teacher-child problem-solving episodes were videotaped. After the collaborative problem solving, we interviewed the adults to investigate their perceptions and familiarity with the tasks, whether or 
not they scaffolded children's problem solving in similar activities in daily life, and the reasons for their specific behaviors during problem solving. Because this report focuses mainly on adults' scaffolding behaviors, data gathered from these interviews are not presented and discussed comprehensively, but they were helpful in understanding the adult-child problemsolving process.

\section{Coding Scaffolding and Responses}

The adult-child interactions in the worksheet task were transcribed for their entire duration (mother-child: $M=3.28, S D=1.71$, duration $=.40-7.90$ min; teacher-child: $M=3.27, S D=2.01$, duration $=.75-9.75 \mathrm{~min})$. The dyads spent much longer on the puzzle task (mother-child: $M=9.24, S D$ $=4.07$, duration $=4.15-23.60 \mathrm{~min}$; teacher-child: $M=7.98, S D=3.17$, duration $=3.83-17.52 \mathrm{~min}$ ) than on the worksheet task. We transcribed and coded only the first $5 \mathrm{~min}$ of adult-child interactions in the puzzle task. We felt this approach was justified because there were no significant differences in either adult behavior or child behavior between the first and second halves of the adult-child interaction sessions for six randomly selected dyads ( $t \mathrm{~s}<.93, p \mathrm{~s}<.05$ ). This suggested that the adults' scaffolding strategies and the children's responses patterns did not change significantly over time, which might be due to their familiarity with the activities. We thus considered that the first half session of the dyadic problem solving in the puzzle task could represent the nature of dyadic interactions in the whole problem-solving process, and only the first $5 \mathrm{~min}$ of the adult-child interactions in the puzzle task were transcribed for the following analyses. Both verbal and nonverbal information was noted in the transcription.

The interaction turn was the unit of analyses. Based on the work by Chin (1995) and Heckhausen (1987), an adult turn and the subsequent child turn comprised one unit for further coding. An adult turn was coded when a pause of more than $5 \mathrm{~s}$ occurred after the adult had made an utterance. A child's turn was defined as all of his or her behaviors between two subsequent adult turns. As long as the participant continued his or her speech or actions without pausing longer than $2 \mathrm{~s}$, the sequential actions or utterances were treated as one turn (Chin, 1995). The adult's scaffolding behaviors and the child's responses were coded for each of the interaction turns. A total of 5,479 turns were analyzed. We anticipated that the coding of adults' scaffolding behaviors and children's responses would effectively illuminate the nature of the scaffolding process.

Adults' scaffolding. Each adult turn was coded to indicate scaffolding content, manner, and level. Scaffolding content focused on specific 
scaffolding information during the interaction: Collaborative scaffolding content was helpful in soliciting children's active learning and higher-order thinking. Scaffolding manner dealt with how the information was delivered to the child: collaborative manner could help involve the child in problem solving to a large extent. Scaffolding level reflected the complexity of adults' scaffolding: scaffolding with more detailed information was easier to follow than general guidance.

Both scaffolding content and scaffolding manner were coded as being collaborative, directive, or unidentified (unidentified scaffolding manner, 8.2\%; unidentified scaffolding content, $13.7 \%$ ). Adults' efforts to involve children's active thinking were regarded as collaborative support. When an adult pushed the problem solving without considering the child as an active and equal agent, the scaffolding was deemed directive. Adults' scaffolding was coded as falling from Level 1 to Level 5. Level 1 represented general assistance, whereas Levels $2-4$ denoted progressively more specific assistance. Interactions were coded as being at Level 5 when adults used physical prompts. If the conversations between the adult and the child were unrelated to the problem-solving steps (for example, before the problem solving started, the adult might greet the child or ask him or her some warm-up questions, such as "do you like playing puzzles?" and "what's the name of this bear in the puzzle?"), no scores for adults' scaffolding were given in these interaction turns (15.8\%). When the adult mixed scaffolding of different levels in one turn, we coded the scaffolding level offered in the last instruction by the adult in the specific turn. We then calculated the difference in adults' scaffolding levels between two contiguous turns. If the scaffolding level in one related turn was missing (that is, the conversations were unrelated to the task), the difference scores for these two interaction turns were not considered in the subsequent analyses.

According to the CSR (Wood et al., 1976), the adult is expected to offer less help when the child performs the problem solving smoothly and provide more help when the child encounters difficulties. However, the CSR does not provide explanations regarding the definitions of "less help" or "more help." Adults could conceivably provide "too much" guidance when children encounter difficulties or be "too detached" when children work successfully and independently. Therefore, we operationally defined adults' adoption of the CSR in the following way: When the child successfully followed the adult's previous instruction, the adult shifted to a level of scaffolding with moderately decreased detail (for example, from Level 3 to Level 2); or, when the child failed to act as adults requested, the adult moved forward to the level with moderately increased detail (for example, from Level 2 to Level 3). Tables 1 and 2 present the detailed description 


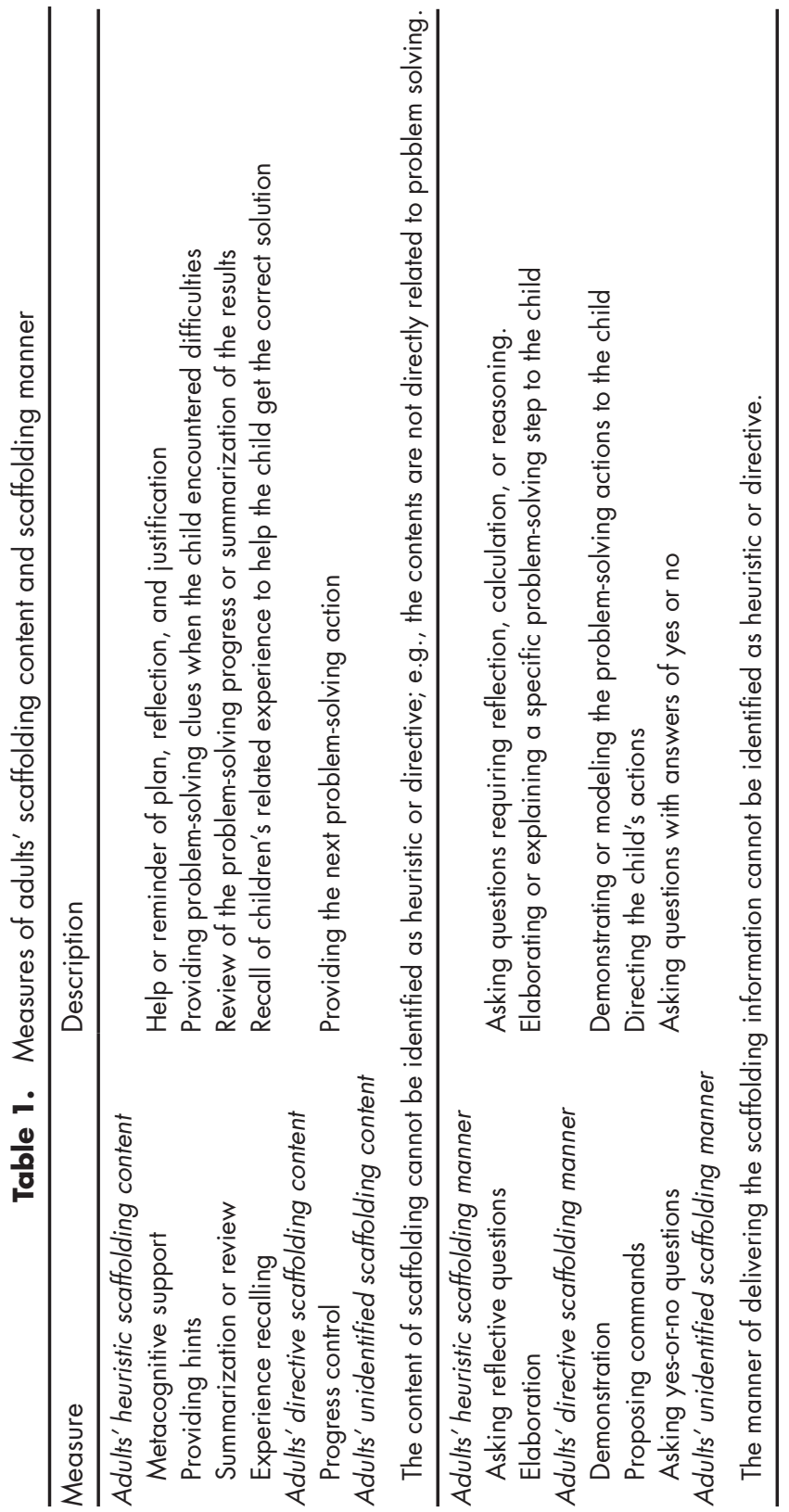




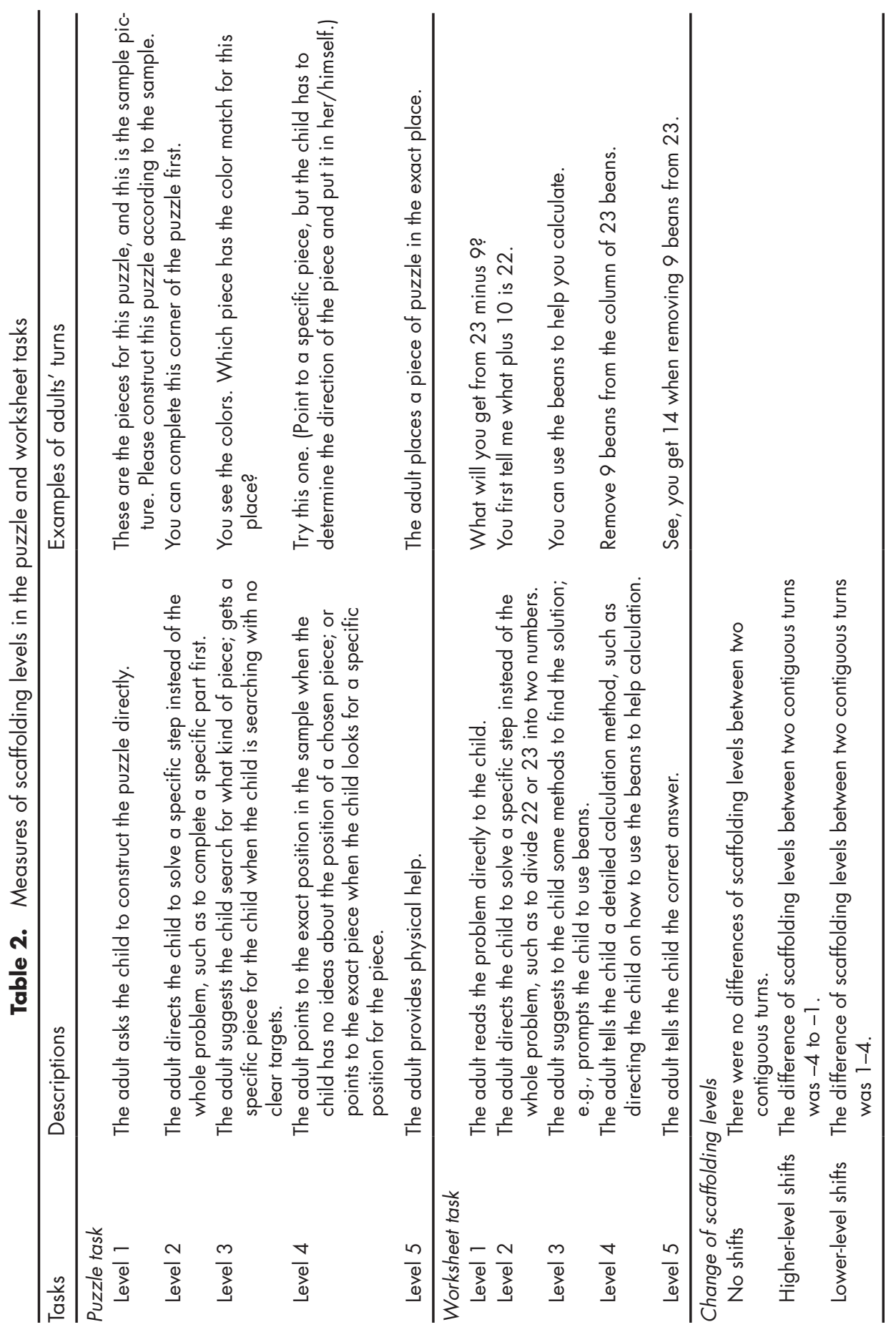


of the measures of the adult's behaviors. Since children's nonresponse was different from children's failure and success, we did not consider the situations in which children did not respond to adults' instructions in the analyses of adults' adoption of the CSR.

Children's behaviors. Children's behaviors were coded according to whether they followed adults' instructions. Children's responses that followed adults' turns and were irrelevant to the problem solving were not included in the analyses. Since a child turn was defined as all the child's behaviors between two subsequent adult turns, every child turn was thus coded as a sequel to the adult's instructions. When the children effectively followed adults' instructions in one interaction turn, their behaviors were coded as "success." If they were unable to benefit from adults' instructions in one interaction turn, or could not act as the adults instructed, children's behaviors were coded as "failure." Aside from obvious success and failure, the children displayed another type of response; that is, no response (NR). We coded the child's behaviors as NR when he or she did not respond to the adult's instructions between two adults' turns. The NR was different from children's failure response (wherein the child made an incorrect response after the adult's instructions) in our coding scheme; when their behaviors were coded as NR, children did not make any explicit behavior or verbal responses after adult instruction. In light of the lack of obvious behavior or verbal clues, this could not be considered as a failure to follow the adult's instructions. Children's responses that were unrelated to adult instructions were coded as "other responses" (3.8\% of the turns). Therefore, four codes for children's behaviors were created: success, failure, NR, and other responses. Since the number of "other responses" was small, only the first three dimensions of children's behaviors were analyzed.

Each interaction turn was multiply coded in terms of scaffolding content (collaborative /directive/unidentified), scaffolding manner (collaborative/directive/unidentified), scaffolding level, and the child's response, with " 1 " representing the occurrence and " 0 " representing nonoccurrence of a specific code. For example, the coding of four interaction turns in a mother-child interaction in the puzzle task is shown below. More examples for specific scaffolding levels in the puzzle and worksheet tasks are presented in Table 2.

Mother: "You find the position for this piece first." [Scaffolding level: 2; scaffolding content: directive; scaffolding manner: directive.]

Child: (in action) Tries several possible positions, but cannot find a correct position. [Child behavior: failure.] 
Mother: "What's the color of that corner? It will be easier to match the color first." [Scaffolding level: 3; scaffolding content: collaborative; scaffolding manner: collaborative.]

CHILD: "It's red." (in action) Picks up one piece with the red color and puts the piece in that position. It is the correct piece. [Child behavior: Success.]

After coding interaction turns, we first counted the frequencies of the adults' collaborative/directive scaffolding content, collaborative/directive scaffolding manner, and differences in scaffolding levels between two contiguous turns (lower-level shift, higher-level shift, no shift) immediately after children's different responses (A). The numbers of children's success, failure, and NR responses that followed instruction(s) from the adult were also determined, since there would be no subsequent instructions from the adult for children's responses (usually it was the success response) in the last turn of interactions (B). Then, the proportions of the adult's collaborative/directive scaffolding content, collaborative/directive scaffolding manner, lower-level shift, higher-level shift, and no shift of scaffolding levels immediately after the child's failure, success, and NR were calculated by dividing A by B. These proportions were treated as the scores for adults' scaffolding in each dimension.

We also considered adults' scaffolding strategies after the child had two consecutive successes, failures, or NRs. We selected the interaction turns immediately after children's two successive successes $(24.9 \%$ of the total number of interaction turns), failures (13.9\%), and NRs (4.1\%) and analyzed adults' subsequent instructions. Similar to the analyses done for adults' scaffolding strategies after the child's one specific response, we also calculated the proportions of adults' collaborative/directive scaffolding content, collaborative/directive scaffolding manner, lower-level shift, higher-level shift, and no shift of scaffolding levels after children executed two consecutively similar responses.

The correlations between collaborative and directive contents (motherchild: $r=-.74, p<.001$; teacher-child: $r=-.74, p<.001)$ and collaborative and directive manners (mother-child: $r=-.75, p<.001$; teacher-child: $r=$ $-.76, p<.001$ ) were relatively high. This indicated that one dependent variable became a near-linear combination of the other (Tabachnick \& Fidell, 2007 , p. 253). It would become statistically redundant and suspect to include both the dependent variables, so the overall scores for the scaffolding content and manner were calculated by reverse coding the directive scaffolding content/manner ( $\mathrm{R}=1$ - the score of directive scaffolding content/ manner) and then averaging $\mathrm{R}$ and the score of collaborative scaffolding 
content/manner, respectively (see Neitzel \& Stright, 2003). Higher scores in each code indicated that the scaffolding content or manner of the adults' instructions in a specific problem-solving task was less directive but more collaborative.

To establish interrater reliability in coding, a Chinese postgraduate student in early childhood education was trained to serve as an independent rater. Four transcripts, one for each task, were randomly selected and used for training. The first step in the training was to introduce and explain the coding framework to the student. When the rater had a clear conception of each code, she and the first author coded the training transcripts together and discussed discrepancies. After the two raters had reached a general agreement, the first author (Rater 1) coded all the interactions, and the student independently coded 16 children's interactions with their mothers and teachers (64 episodes). The percentages of agreement in different scaffolding indicators for each turn between two coders ranged from $92 \%$ to $97 \%$, and Cohen's kappa ranged from .85 to .90 .

\section{Results}

\section{Construct Validity of the Scaffolding Measures}

Following the approaches used by Pratt et al. (1988), we first examined the construct validity of the scaffolding measures. Correlations between the children's successful responses and the adults' different scaffolding levels in the puzzle and worksheet tasks were calculated. Consistent with the findings of Pratt et al. (1988) and of Wood and Middleton (1975), the results showed that, with the reduction of complexity in adults' instructions, children's success rate increased. In both of the tasks, the percentage of children's success after adults' Level 4 scaffolding was significantly greater than that after the Level 3 and Level 2 scaffolding, which were also significantly greater than that after the Level 1 scaffolding $\left(\chi^{2}>45.08, p s<.001, V>.89\right)$. We thus considered that the measure of scaffolding levels was sensitive in capturing the various complexities in the adults' scaffolding.

The most common scaffolding level at which children could generally follow adults' scaffolding successfully was different in the puzzle and worksheet tasks. In the puzzle task, children could normally successfully follow adults' instructions at Level 3 and below (72.0\%), but, in the worksheet task, the most frequent scaffolding level at which children could successfully follow instructions was Level 4 and below (73.6\%). This suggested that the measure of scaffolding levels was also sensitive to the task characteristics. 
Finally, we examined the correlations between scaffolding content, scaffolding manner, and children's success rate. For both mothers and teachers, the scaffolding content and manner were positively correlated in the puzzle (mothers: $r=.56, p<.001$; teachers: $r=.45, p<.001$ ) and worksheet tasks (mothers: $r=.27, p<.05$; teachers: $r=.39, p<.01$ ). Since the measures of scaffolding content and manner were consistent across the tasks, these results indicated the effectiveness of these measures in capturing the collaborative information in the scaffolding: the collaborative scaffolding content was more likely to be delivered in a collaborative way. Neither scaffolding content nor manner was significantly correlated with children's success rate in each task. This is logical as children's ability to follow adults' instructions successfully was more likely to be a function of task complexity than of the extent to which adults' showed collaborative scaffolding content and manner.

\section{Scaffolding After Children's One Specific Response}

The partner order and gender effects are not considered in the following analyses because no related effects on the adults' scaffolding and the children's responses were found. Table 3 presents the means and standard deviations of children's different responses in mother-child and teacherchild interactions in the two tasks. Since this article focuses on adults' scaffolding strategies in terms of children's different responses, we do not analyze the variations in children's responses in different adult-child problem-solving tasks.

Table 4 presents the results of multiple contrasts of adults' scaffolding content, scaffolding manner, and shifts of scaffolding levels immediately after children's one or two specific responses.

Three 2 (partner: mothers vs. teachers) $\times 2$ (SES: lower vs. middle or upper) $\times 2$ (task: puzzle vs. worksheet) multivariate analyses of variance (MANOVAs) with task as the within-subject variable were performed with adults' scaffolding content, scaffolding manner, and shifts of scaffolding levels after children's specific responses as dependent variables, to examine adults' scaffolding in response to children's one failure, success, and NR. Tukey's honestly significant difference test was used for post hoc comparisons with $p$ set at .05 for examinations of interaction effects. Only two-way interaction effects were considered, given the research objectives.

Scaffolding after children's one failure. The omnibus analyses yielded significant effects of partner, $F(5,51)=5.50, p<.001, \eta_{p}{ }^{2}=.35$; task, $F(5$, $51)=8.98, p<.001, \eta_{p}{ }^{2}=.47$; and Partner $\times \operatorname{SES}, F(5,51)=3.51, p<.01$, $\eta_{p}{ }^{2}=.26$. The teachers showed more lower-level shifts $(M=.29, S D=.15)$, 
Table 3. Means and standard deviations of children's different responses in different adult-child problem-solving tasks

\begin{tabular}{llllll}
\hline & \multicolumn{2}{c}{ Mother-child } & & \multicolumn{2}{c}{ Teacher-child } \\
\cline { 2 - 3 } Children's responses & Puzzle & Worksheet & & Puzzle & Worksheet \\
\hline Successful following instructions & $.31(.25)$ & $.44(.24)$ & & $.39(.19)$ & $.53(.20)$ \\
Failure to follow instructions & $.51(.24)$ & $.35(.21)$ & & $.40(.16)$ & $.27(.17)$ \\
No response (NR) & $.12(.17)$ & $.15(.16)$ & & $.19(.16)$ & $.19(.17)$ \\
\hline
\end{tabular}

adopted more collaborative scaffolding manners $(M=.48, S D=.18)$, and maintained the scaffolding level $(M=.60, S D=.19)$ more frequently than mothers (lower-level shifts: $M=.24, S D=.14$; scaffolding manner: $M=$ $.39, S D=.18$; maintenance of scaffolding levels: $M=.50, S D=.17$ ) in response to children's one failure response. In the worksheet task, the adults showed more maintenance of scaffolding levels $(M=.64, S D=.19)$, fewer lower-level shifts $(M=.22, S D=.18)$ and higher-level shifts $(M=.12, S D=$ $.12)$, a higher collaborative level of scaffolding manner $(M=.49, S D=.22)$ than in the puzzle task (no shifts: $M=.46, S D=.16$; lower-level shifts: $M=$ $.31, S D=.13$; higher-level shifts: $M=.19, S D=.11$; scaffolding manner: $M=.37, S D=.14)$.

Table 4. Multiple contrasts of adults' scaffolding modifications across children's different responses

\begin{tabular}{lccc}
\hline \multicolumn{1}{c}{$\begin{array}{c}\text { After failure } \\
M(S D)\end{array}$} & $\begin{array}{c}\text { After success } \\
M(S D)\end{array}$ & $\begin{array}{c}\text { After NR } \\
M(S D)\end{array}$ \\
\hline After children's one specific response & & \\
No shifts & $.55(.14)_{a}$ & $.44(.12)_{b}$ & $.57(.14)_{b}$ \\
Lower-level shifts & $.26(.12)_{a}$ & $.16(.07)_{b}$ & $.31(.14)_{a}$ \\
Higher-level shifts & $.15(.09)_{a}$ & $.35(.10)_{b}$ & $.10(.08)_{c}$ \\
Content & $.55(.14)_{a}$ & $.28(.10)_{b}$ & $.52(.13)_{a}$ \\
Manner & $.43(.12)_{a}$ & $.45(.11)_{a}$ & $.46(.16)_{a}$ \\
\hline After children's two consecutive similar responses & & \\
No shifts & $.50(.18)_{a}$ & $.40(.17)_{b}$ & $.39(.27)_{a}, b$ \\
Lower-level shifts & $.32(.16)_{a}$ & $.16(.14)_{b}$ & $.45(.21)_{a}$ \\
Higher-level shifts & $.16(.11)_{a}$ & $.38(.18)_{b}$ & $.12(.10)_{a}$ \\
Content & $.58(.12)_{a}$ & $.28(.11)_{b}$ & $.48(.14)_{c}$ \\
Manner & $.43(.13)_{a}$ & $.45(.15)_{a}$ & $.44(.14)_{a}$ \\
\hline
\end{tabular}

Note. Means in the same row that do not share the same subscript differ at $p<.05$ in the pairwise comparison. 
The significant Partner $\times$ SES effect for scaffolding content indicated that the middle or upper SES mothers $(M=.56, S D=.18)$ showed more collaborative scaffolding content than the lower SES mothers $(M=.44$, $S D=.16$ ), and no significant differences between the teachers' scaffolding content after children's failure for middle or upper SES and lower SES children (middle or upper SES: $M=.60, S D=.16$; lower SES: $M=.56$, $S D=.18$ ). The lower SES children received more collaborative scaffolding content from the teachers after their failure than from the mothers; no significant differences were found between the mothers' and teachers' scaffolding content for the middle or upper SES children after their failure.

Scaffolding after children's one success. The repeated-measures MANOVA examining adults' scaffolding modification after children's one successful response revealed significant effects of partner, $F(5,51)=2.89$, $p<.05, \eta_{p}^{2}=.22$; and task, $F(5,51)=12.23, p<.001, \eta_{p}{ }^{2}=.55$. The teachers $(M=.50, S D=.15)$ showed a more highly rated scaffolding manner than the mothers $(M=.41, S D=.18)$. Significantly more maintenance of scaffolding levels, fewer higher-level shifts, and a higher collaborative level of scaffolding manner were found in the worksheet task (no shifts: $M=.51, S D=.15$; higher-level shifts: $M=.31, S D=.12$; scaffolding manner: $M=.51, S D=.15$ ) than in the puzzle task (no shifts: $M=.37, S D=$ .16; higher-level shifts: $M=.39, S D=.15$; scaffolding manner: $M=.40$, $S D=.15)$.

Scaffolding after children's one NR. Significant effects of partner, $F(5,51)=4.44, p<.01, \eta_{p}{ }^{2}=.30$; task, $F(5,51)=10.72, p<.001, \eta_{p}{ }^{2}=$ .51 ; and Task $\times \operatorname{SES}, F(5,51)=9.49, p<.001, \eta_{p}{ }^{2}=.48$, were found in the omnibus analyses of adults' scaffolding after children's NR. The teachers were more likely to maintain their scaffolding levels $(M=.62, S D=.19)$, or showed less higher-level shifts $(M=.08, S D=.11)$, after children's one NR and showed more collaborative scaffolding content $(M=.57, S D=$ $.19)$ and manner $(M=.50, S D=.25)$ than the mothers (no shifts: $M=.52$, $S D=.23$; higher-level shifts: $M=.13, S D=.12$; scaffolding content: $M=$ $.46, S D=.17$; scaffolding manner: $M=.41, S D=.18$ ). Significantly more higher-level shifts in scaffolding levels after children's NR were found in the puzzle $(M=.16, S D=.15)$ than in the worksheet task $(M=.05, S D=$ $.06)$, but more maintenance of scaffolding levels was found in the worksheet task $(M=.65, S D=.25)$ than in the puzzle task $(M=.49, S D=.18)$ after children's one NR.

When they failed to respond, the lower SES children received significantly more collaborative scaffolding content in the worksheet $(M=.56$, $S D=.12)$ than in the puzzle task $(M=.44, S D=.18)$; the scaffolding content for the middle or upper SES children did not differ significantly in 
the two tasks (puzzle: $M=.53, S D=.17$; worksheet: $M=.53, S D=.15$ ). The middle or upper SES children received significantly more collaborative scaffolding content than the lower SES children after they had made NR in the puzzle task, but no significant differences of scaffolding content were found between these two groups of children in the worksheet task.

In addition, the scaffolding manner for the lower SES children after their NR was rated significantly higher in the worksheet task $(M=.60$, $S D=.18)$ than in the puzzle $(M=.30, S D=.15)$; no significant differences in scaffolding manner for the other children were found between the puzzle $(M=.48, S D=.22)$ and worksheet $(M=.45, S D=.24)$ tasks. The middle or upper SES children received significantly higher-rated scaffolding manner after their NR than the lower SES children in the puzzle task, and there were no significant differences of scaffolding manner for the two groups of children in the worksheet task.

Adoption of the CSR after children's one success or failure. Scaffolding was deemed appropriate when an adult provided more help when the child encountered difficulties and less when the child could solve the problem. However, the scaffolding was considered not optimal when the adult provided too much specific assistance when the child was stuck at one problem-solving step, or when the adult withdrew her help too quickly when the child had a specific success. Therefore, adults' adoption of CSR is further examined in this section.

A 2 (partner: mothers vs. teachers) $\times 2$ (SES: lower vs. middle or upper) $\times 2$ (task: puzzle vs. worksheet) repeated-measures analysis of variance (ANOVA), with task as the within-subject variable, for adults' adoption of the CSR showed significant effects of partner, $F(1,55)=15.07, p<.001$, $\eta_{p}{ }^{2}=.22$; and Partner $\times$ SES, $F(1,55)=12.89, p<.01, \eta_{p}{ }^{2}=.19$. The teachers of lower SES children $(M=.15, S D=.06)$ applied the CSR significantly more often than mothers $(M=.06, S D=.06)$, but teachers' and mothers' adoption of the CSR for the children from the middle or upper SES families did not differ significantly (teacher: $M=.12, S D=.05$; mother: $M=.11$, $S D=.08$ ). In addition, the middle or upper SES mothers adopted the CSR more frequently than did the other mothers, but the teachers' adoption of the CSR for the two groups of children did not differ significantly.

\section{Scaffolding Shifts After Children's Two Consecutive Similar Responses}

The results of adults' scaffolding strategies based on children's one specific response showed that the adults were more likely to maintain the scaffolding level of the previous turn no matter what response the child made, and 
the adults showed a higher collaborative level of scaffolding content after children's failure and NR. We were wondering whether this pattern of scaffolding behaviors still existed for adults' scaffolding strategies after the child had made two consecutive similar responses.

Table 4 also presents adults' scaffolding adjustment after children had made two consecutive similar responses. As Figures 1-3 show, the adults were less likely to maintain the previous scaffolding levels, $t(56)=2.35$, $p<.05, d=.31$, but made more lower-level shifts when the child failed to follow their instructions on two consecutive occasions, $t(56)=2.62, p<$ $.05, d=.43$, than after children's one specific response. When the child did not respond to the adult's instructions in two successive turns, the adults were less likely to maintain their scaffolding levels, $t(56)=2.50, p<.05$, $d=.77$, and more likely to show lower-level shifts, $t(56)=1.97, p<.05$, $d=.60$, compared with adults' scaffolding adjustment in response to children's one NR. The adults also adopted the CSR more frequently after two consecutive successes or failures $(M=.34, S D=.18)$ than after one success or failure $(M=.09, S D=.04), t(56)=11.60, p<.001, d=2.27$.

After these preliminary analyses of adults' scaffolding strategies after children's consecutive similar responses, we conducted another three 2 (partner: mothers vs. teachers) $\times 2$ (SES: lower vs. middle or upper) $\times 2$ (task: puzzle vs. worksheet) repeated-measures MANOVAs, with task as the within-subjects variable, to examine whether adults' scaffolding strategies in these situations differed significantly across different partners and tasks. We also used Tukey's honestly significant difference test for post hoc comparisons with $p$ set at .05 .

Scaffolding after children's two successive failures. Significant effects of partner, $F(5,51)=4.81, p<.001, \eta_{p}{ }^{2}=.32$; task, $F(5,51)=12.70, p<$ $.001, \eta_{p}{ }^{2}=.56$; and Partner $\times \operatorname{SES}, F(5,51)=2.92, p<.05, \eta_{p}{ }^{2}=.22$, were found in the omnibus analyses of adults' scaffolding shifts after children's two successive failures. On average, adults maintained the previous scaffolding level more frequently in the worksheet task $(M=.63, S D=.32)$ than in the puzzle task $(M=.37, S D=.16)$ and made more lower-level and higher-level shifts in the puzzle task (lower-level: $M=.38, S D=.19$; higher-level: $M=.21, S D=.16$ ) than in the worksheet task (lower-level: $M=.25, S D=.20$; higher-level: $M=.12, S D=.10$ ) when children made two consecutive failure responses. They also adopted a higher collaborative level of scaffolding content and manner in the worksheet task (scaffolding content: $M=.62, S D=.20$; scaffolding manner: $M=.55, S D=.24$ ) than in the puzzle task (scaffolding content: $M=.54, S D=.15$; scaffolding manner: $M=.31, S D=.17$ ) when children could not follow their instructions in two successive turns. 


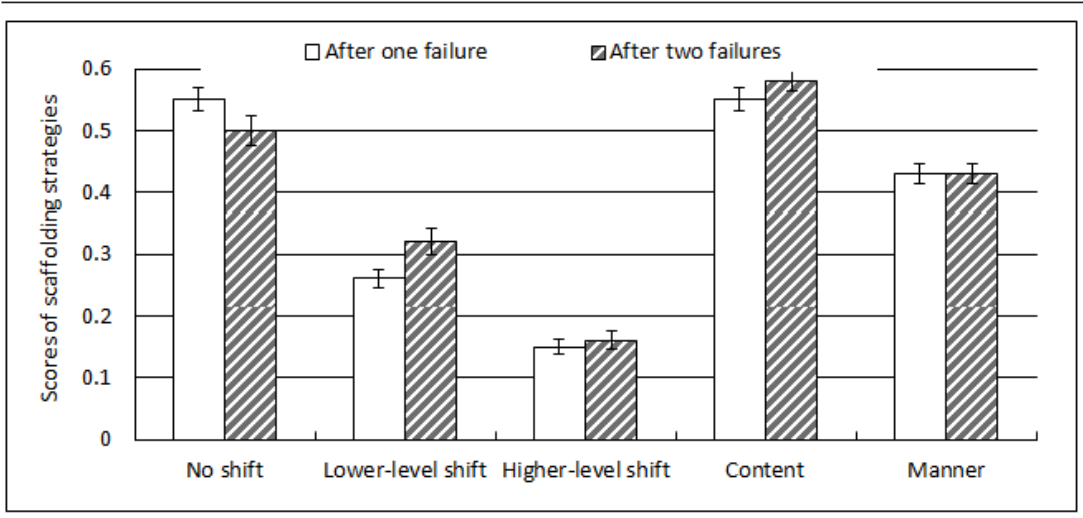

Figure 1. Comparison of adults' scaffolding strategies after children's one failure and two consecutive similar failures.

In addition, the lower SES mothers showed a lower level of collaborative scaffolding manner $(M=.35, S D=.14)$ than the teachers $(M=.56$, $S D=.18$ ), but no significant differences were found between the scaffolding manner of the middle or upper SES mothers $(M=.39, S D=.18)$ and the teachers $(M=.43, S D=.21)$.

Scaffolding after children's two successive successes. The repeatedmeasures MANOVA yielded significant effects of partner, $F(5,51)=6.38$, $p<.001, \eta_{p}^{2}=.39$; task, $F(5,51)=3.58, p<.01, \eta_{p}{ }^{2}=.26$; and Task $\times$ SES, $F(5,51)=3.91, p<.01, \eta_{p}^{2}=.23$, for adults' scaffolding strategies in response to children's two consecutive successes. The teachers $(M=.52$,

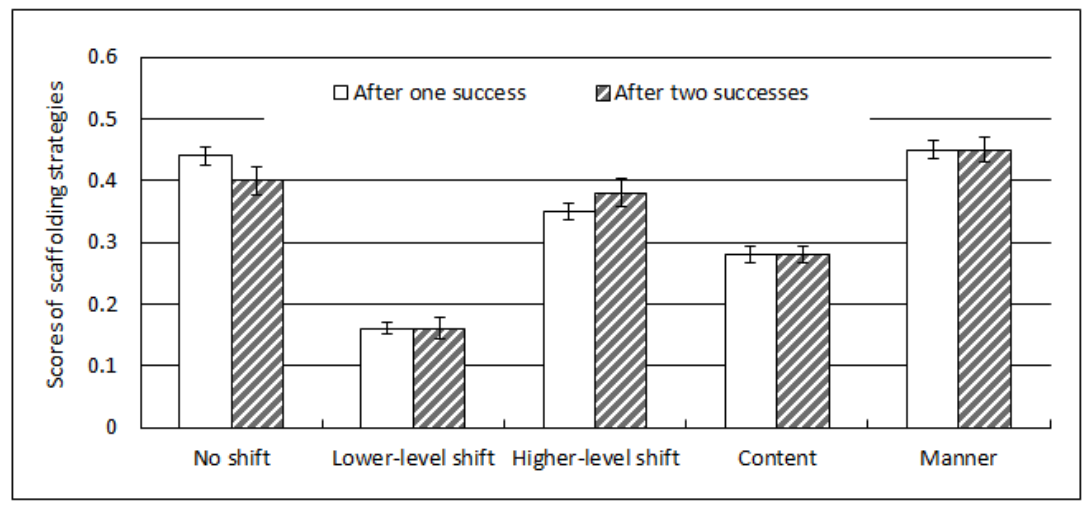

Figure 2. Comparison of adults' scaffolding strategies after children's one success and two consecutive similar successes. 


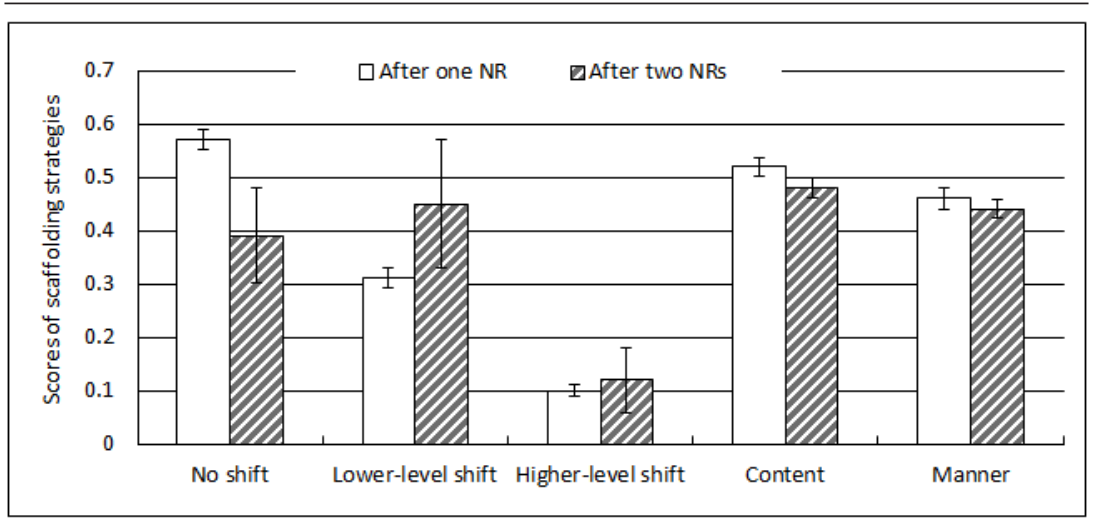

Figure 3. Comparison of adults' scaffolding strategies after children's one "no response" (NR) and two consecutive similar NRs.

$S D=.19)$ also adopted a higher collaborative level of scaffolding manner than did the mothers $(M=.38, S D=.18)$, and the scaffolding manner used in the worksheet task $(M=.49, S D=.20)$ was more collaborative than in the puzzle task $(M=.42, S D=.19)$. Despite the significant Task $\times$ SES effect found in the omnibus analyses, the post hoc tests did not find significant differences in the scaffolding strategies received by children from different SES backgrounds in the two tasks.

Scaffolding after children's two successive NRs. There were significant effects of partner, $F(5,51)=27.11, p<.001, \eta_{p}{ }^{2}=.73$; task, $F(5,51)$ $=47.63, p<.001, \eta_{p}^{2}=.82$; and Partner $\times$ Task, $F(5,51)=12.40, p<.001$, $\eta_{p}^{2}=.55$, in the repeated-measures MANOVA examining adults' scaffolding strategies in response to children's two consecutive NRs. The teachers exerted a higher collaborative level of scaffolding manner $(M=.55, S D=$ $.24)$ than the mothers $(M=.32, S D=.09)$ after children's two successive NRs. The adults also adopted a higher collaborative level of scaffolding manner in the worksheet task $(M=.57, S D=.15)$ than in the puzzle task $(M=.31, S D=.15)$. In addition, the mothers adopted a significantly higher collaborative level of scaffolding content in the worksheet task $(M=.51$, $S D=.17)$ than in the puzzle task $(M=.26, S D=.21)$. The scaffolding content used by the mothers in the puzzle task was also of a significantly lower collaborative level than that used by the teachers $(M=.57, S D=.26)$.

Adoption of the CSR after children's successively two successes or failures. We conducted a 2 (partner: mothers vs. teachers) $\times 2$ (SES: lower vs. middle or upper) $\times 2$ (task: puzzle vs. worksheet) repeated-measures ANOVA, with task as the within subject variable, for adults' adoption of 
the CSR, which showed significant effects of partner, $F(1,55)=9.82, p<$ $.001, \eta_{p}{ }^{2}=.15$; and Partner $\times$ Task, $F(1,55)=5.92, p<.05, \eta_{\mathrm{p}}{ }^{2}=.10$. The teachers $(M=.45, S D=.37)$ adopted the CSR significantly more frequently than did the mothers $(M=.26, S D=.25)$ in the worksheet task, but no significant differences were found between the mothers $(M=.33, S D=.26)$ and teachers $(M=.33, S D=.29)$ in the puzzle task.

\section{Adults' Understanding of the Tasks and Interpretation of Their Scaffolding Behaviors}

After the problem-solving session, we informally asked the adults why they had showed specific scaffolding adjustment in the dyadic problem solving. The most common explanation for their maintenance of scaffolding levels after children's different responses was that they wanted to confirm the children's understanding of their guidance (more than $60 \%$ of the mothers and $90 \%$ of the teachers), and they stated that they would change the complexity of their instructions only after they had ascertained whether the children could follow the instruction with a specific level of complexity.

All mothers and teachers acknowledged that the children should be responsible for the problem solving and be involved to the maximum extent possible in the task, but felt they had to help the children proceed on the right track in this process. Therefore, they believed that it was necessary to provide specific problem-solving steps for the children.

Most of the mothers reported that they had puzzles (89.5\%) and worksheets $(96.1 \%)$ at home for their children. All teachers, except one, reported that there were puzzles in their classrooms, and all teachers stated that they assigned worksheet exercises to children. However, both mothers and teachers reported that they rarely provided step-by-step guidance for individual children to complete a puzzle task (91.2\% of the mothers; $70.5 \%$ of the teachers).

\section{Discussion}

This study examined scaffolding processes in dyadic problem solving and compared mothers and teachers' scaffolding of 5-year-olds in Beijing, China. It also considered the influence of SES and task characteristics on the dyadic interactions.

\section{Influences of Partner Characteristics on Adults' Scaffolding}

The results support the hypothesis that professional training in early childhood education and family socioeconomic (SES) background would be 
related to adults' scaffolding modifications in reaction to children's responses. In keeping with the predictions, teachers made more appropriate shifts in their scaffolding levels after children's failure or NR and provided a higher level of collaborative scaffolding manner than mothers. These results suggest that their professional training in early childhood education may have helped the teachers to be more sensitive to children's responses and to adjust their scaffolding behaviors in the dyadic interactions. Professional training may also have helped teachers establish collaborative relationships with children in problem solving. However, teachers' superiority to mothers was not evident in all indicators related to scaffolding modification, especially when children successfully followed previous instructions. These findings suggest that teachers may not have been reflective and skilled enough to further the scaffolding process when their previous instructions had been successfully followed.

Our hypothesis that mothers from the lower SES group would be less skilled in providing appropriate scaffolding after children's different behaviors than those from middle or upper SES backgrounds was partially supported. The influences of family SES background were evident in the level of adults' adoption of collaborative scaffolding content and manner when children followed adults' instructions successfully, but not in adults' shifts of scaffolding levels and the scaffolding strategies after children's failure or NR. Adults may be more familiar with the practice of offering more help when children have difficulties and less when children can solve the problem smoothly than of the notion of working collaboratively with the child in dyadic problem solving. However, families from the middle or upper SES background may have more resources than those from lower SES background to help mothers form a better understanding of collaborative problem solving, and enable mothers to be more sensitive to their children's specific needs and provide appropriate support accordingly. These findings further indicate that the influences of SES on adults' scaffolding skills are not straightforward (Hoff, Laursen, \& Tardif, 2002; Leseman \& Sijsling, 1996; Zegiob \& Forehand, 1975): they may depend more on the specific facets of scaffolding behaviors studied and may be context dependent.

\section{Influences of Task Characteristics on Adults' Scaffolding}

Our assumption that more appropriate scaffolding would be evident in the worksheet task was also partially supported. The scaffolding in the worksheet task was more collaborative than that in the puzzle task. Adults were more cautious about changing their scaffolding levels in the worksheet 
task, and more shifts of scaffolding levels were found in the puzzle task (in both appropriate and inappropriate directions). Such differences in scaffolding behaviors may have been associated with the adults' different understandings of the nature of tasks.

Chinese mothers and teachers distinguish between play and learning and may conceptualize solving puzzles as play but not a learning activity. Hence, they have fewer experiences of completing puzzles with children. This may result in less collaboration with children and less skilled adjustments of scaffolding levels in the puzzle task. In contrast, the worksheet task is a typical school learning activity, and academic learning is highly stressed in the Chinese culture. To prepare children in the final level of kindergarten for primary school, Chinese mothers and teachers normally reinforce formal mathematical learning knowledge in children's daily activities (Huntsinger, Jose, Liaw, \& Ching, 1997; Stevenson \& Stigler, 1992). Thus, it is understandable that both mothers and teachers were more likely to provide appropriate adjustment of scaffolding in the worksheet task.

\section{Combined Influences of Partner and Task Characteristics on Adults' Scaffolding}

The influences of task characteristics on adults' scaffolding behaviors differed across children from different SES backgrounds. After children's success and NR, the low SES children received more collaborative scaffolding content and manner in the worksheet task than the middle and upper SES children, and the help for the children from middle or upper SES families did not differ significantly between these two tasks. These findings are consistent with those reported by Renshaw and Gardner (1990), who found that adults employed more indirect strategies when the problem-solving task was interpreted as learning-oriented, but more directive strategies when the task was conceptualized as product-oriented. Nevertheless, the findings also specify the influence of SES on the scaffolding modification in these two types of tasks within the Chinese context.

Teachers of children from the lower SES group provided a lower collaborative level of scaffolding for their students in the puzzle task than other teachers. Although this finding is not in keeping with our predictions, it may again reflect Chinese parents' expectations for their children's early achievement (Chi \& Rao, 2003). For lower SES families, education is not only related with children's personal development but is also regarded as the only path to upward social mobility; this is not the case for middle or upper SES families. Such expectations may both direct mothers' behaviors in interactions with children and influence teachers' instructions 
in kindergartens. At the same time, fewer resources and less support are available for teachers of children from lower SES families than for teachers of middle or upper SES children (Duke, 2000). To prepare these children for primary schools with limited resources, as well as to satisfy parents, their kindergarten teachers have to stress children's academic performance. In addition, relatively few educational resources are available for teachers in kindergartens catering mainly to lower SES children and a lack of in-service training for these teachers to improve their scaffolding skills in playlike activities. As a result, children from lower SES families may actually have fewer opportunities to play with toys and fewer opportunities to develop learning interests in nonacademic domains, compared to those from middle or upper SES families.

\section{Influences of Children's Responses on Adults' Scaffolding}

Adults exerted more appropriate shifts of scaffolding levels after children's two consecutive failures and NRs than they did after one, but such differences were not found when children were able to follow adults' instructions successfully. The adults also adopted more CSRs after two consecutive successes or failures than after children had made one response. These results supported our hypothesis that more information from children's responses could help adults adopt more appropriate adjustment in their scaffolding.

As indicated in the informal interview, the adults wanted to determine whether the children could actually understand the instructions provided before making changes in their scaffolding levels. Adults may have been more likely to maintain the prior scaffolding level after a failure or NR. This enabled them to gauge better the children's readiness to benefit from adults' feedback, including the children's capability to meet task demands and their motivation to be involved in the problem solving (Chak, 2001), which is vital in effective scaffolding (Plumert \& Nichols-Whitehead, 1996).

After the children's success, the adults should have attempted to move the children to a higher level of understanding. However, they seldom changed their scaffolding levels after the children's success. This suggests that adults are less skilled in asking children more challenging or demanding questions than in reducing the complexity of their instructions. Both preservice and in-service teacher education and parental programs should address this issue. We should also be mindful that optimal scaffolding in adult-child problem solving may not always entail a shift of scaffolding level after every response by the child; indeed, it may be more reasonable for adults to make moderate shifts of scaffolding when they 
have accurately gauged children's level of understanding. This supports Kermani and Brenner's (2000) assertion that it is not adult nondirectiveness, but sensitivity in collaborative work, that is the critical component in promoting young children's learning.

This study extended the examination of the dynamic nature of scaffolding in the Chinese context by pointing out commonalities across cultures and specific characteristics that may be associated with the unique cultural context. Our results first examined the general scaffolding process, which has previously been studied only in Western countries, in the Chinese context. As in Western countries, we found that family SES influenced the scaffolding children received (e.g., Hoff, Laursen, \& Tardif, 2002; Leseman \& Sijsling, 1996) and teachers were able to provide significantly more professional scaffolding than were mothers (Hess et al., 1979; Wertsch et al., 1984). The Chinese mothers and teachers were also likely to shift their scaffolding according to the children's responses (e.g., Gauvain \& Perez, 2008).

At the same time, both teachers and mothers in this study were more likely to show optimal shifts and collaborative scaffolding in the worksheet task (a school-like task) than in the puzzle (a playlike task), which reflects the strong emphasis on children's academic performance in Asian societies (Goyette \& Xie, 1999). However, as our study was conducted in only one city, we are not able to draw conclusions as to whether this finding is specific to the Chinese context. The existing literature on Chinese beliefs helps us interpret the findings from a (single) cultural perspective, but further studies with dyads from different cultural backgrounds are needed in order to determine whether our findings are pan-culturally robust.

There are other limitations to this study. First, the sample size was relatively small, and the participants were recruited in urban China. Further studies should deploy larger sample sizes and from diverse regions. Second, one teacher solved the problems with several different children in her class. The repeated-measures MANOVAs may underestimate the correlated error terms for dyads involving the same teacher for different children. However, we did not explore the influences of teachers' personal characteristics on children's responses, but simply examined how children's behaviors influenced teachers' scaffolding behaviors. In doing so, we tacitly assumed that the influence of teacher personality was minimal. Future large studies should consider the multilevel nature of teacher data. Third, the two tasks used in the study may have restrained variations in adult scaffolding behaviors. Although these tasks were selected after a rigorous and comprehensive process, future studies containing more tasks in one specific category will help us understand better how task differences influence adults' scaffolding. Finally, we did not obtain systematic 
information about adults' educational beliefs and their interpretation of the tasks and appropriate behaviors in these tasks. Therefore, we could not directly examine the association between adults' beliefs and their scaffolding behaviors. Our discussion concerning the influences of adults' beliefs on their scaffolding behaviors was mostly based on the well-documented literature on Chinese parental beliefs. Future studies should address adults' beliefs and interpretations of their behaviors comprehensively and consider links between specific beliefs and scaffolding behaviors.

Despite these limitations, this research demonstrates for the first time the dynamics of Chinese adult-child problem solving and the variations in mothers' and teachers' scaffolding adjustments upon children's different responses in playlike and school-like activities. It also considers SES influences on Chinese adults' scaffolding behaviors. Results have implications for early childhood teacher education and parent training programs for families from different SES backgrounds.

\section{References}

Beijing Educational Committee. (2000). Kindergarten banding regulations and rules in Beijing. Beijing: Chinese government.

Beijing Educational Committee. (2006). Regulations for the implementation of guidelines for kindergartens in Beijing (tentative). Beijing: Tongxin Press.

Chak, A. (2001). Adult sensitivity to children's learning in the zone of proximal development. Journal for the Theory of Social Behaviour, 31, 383-395. doi:10.1111/1468-5914.00166

Chao, R. K. (1994). Beyond parental control and authoritarian parenting style: Understanding Chinese parenting through the cultural notion of training. Child Development, 65, 1111-1119. doi:10.1111/j.1467-8624.1994.tb00806.x

Chi, J., \& Rao, N. (2003). Parental beliefs about school learning and children's educational attainment: Evidence from rural China. Ethos, 31, 330-356. doi:10.1525/eth.2003.31.3.330

Chin, J. C. (1995). Scaffolding-related interactions and strategies during joint play of Taiwanese mothers and children. Unpublished doctoral dissertation, University of Texas at Austin.

Chiu, L. H. (1987). Child-rearing attitudes of Chinese, Chinese-American, and Anglo-American mothers. International Journal of Psychology, 22, 409-419. doi:10.1080/00207598708246782

Conner, D. B., \& Cross, D. R. (2003). Longitudinal analysis of the presence, efficacy and stability of maternal scaffolding during informal problem-solving interactions. British Journal of Developmental Psychology, 21, 315-334. doi:10.1348/026151003322277720 
Duke, N. (2000). Print environments and experiences offered to first-grade students in very low- and very high-SES school districts. Reading Research Quarterly, $35,456-457$.

Farran, D. C., \& Haskins, R. (1980). Reciprocal influence in the social interactions of mothers and three-year-old children from different socioeconomic background. Child Development, 51, 780-791. doi:10.1111/1467-8624.ep12330462

Freund, L. S. (1990). Maternal regulation of children's problem-solving behavior and its impact on children's performance. Child Development, 61, 113-126. doi:10.1111/1467-8624.ep9102040547

Gauvain, M., \& Perez, S. M. (2008). Mother-child planning and child compliance. Child Development, 79, 761-775. doi:10.1111/j.1467-8624.2008.01156.x

Gonzalez, M. M. (1996). Tasks and activities. A parent-child interaction analysis. Learning and Instruction, 6, 287-306. doi:10.1016/S0959-4752(96)00017-5

Goyette, K., \& Xie, Y. (1999). Educational expectation of Asian American youths: Determinants and ethnic differences. Sociology of Education, 72, 22-36.

Harris, Y., Terrel, D., \& Allen, G. (1999). The influence of education context and beliefs on the teaching behavior of African American mothers. Journal of Black Psychology, 25, 490-503. doi:10.1177/0095798499025004002

Heckhausen, J. (1987). Balancing for weaknesses and challenging developmental potential:A longitudinal study of mother-infant dyads in apprenticeship interactions. Developmental Psychology, 23, 762-770. doi:10.1037/0012-1649.23.6.762

Hess, R. D., Dickson, W. P., Price, G. G., \& Leong, D. J. (1979). Some contrasts between mothers and preschool teachers in interaction with 4-year-old children. American Educational Research Journal, 16, 307-316. doi:10.3102/00028312016003307

Hoff, E., Laursen, B., \& Tardif, T. (2002). Socioeconomic status and parenting. In M. H. Bornstein (Ed.), Handbook of parenting: Vol. 2. Biology and ecology of parenting (2nd ed., pp. 231-252). Mahwah, NJ: Erlbaum.

Huntsinger, C. S., Jose, P. E., Liaw, F.-R., \& Ching, W. D. (1997). Cultural differences in early mathematics learning: A comparison of Euro-American, Chinese-American, and Taiwan-Chinese families. International Journal of Behavioral Development, 21, 371-388. doi:10.1080/016502597384929

Kermani, H., \& Brenner, M. E. (2000). Maternal scaffolding in the child's zone of proximal development across tasks: Cross-cultural perspectives. Journal of Research in Childhood Education, 15, 30-52.

Kermani, H., \& Janes, H. A. (1999). Adjustment across tasks in maternal scaffolding in low-income Latino immigrant families. Hispanic Journal of Behavioral Sciences, 21, 134-153. doi:10.1177/0739986399212002

Langry, S. H., Garner, P. W., Swank, P. R., \& Baldwin, C. D. (1996). Effects of maternal scaffolding during joint toy play with preterm and full-term infants. Merrill-Palmer Quarterly, 42, 177-199. 
Leseman, P. P. M., \& Sijsling, F. F. (1996). Cooperation and instruction in practical problem solving: Differences in interaction styles of mother-child dyads as related to socio-economic background and cognitive development. Learning and Instruction, 6, 307-323. doi:10.1016/S0959-4752(96)00018-7

Lin, C. Y. C., \& Fu, V. R. (1990). A comparison of child-rearing practices among Chinese, immigrant Chinese, and Caucasian-American parents. Child Development, 61, 429-433. doi:10.1111/1467-8624.ep5878992

Liu, M., Chen, X., Rubin, K. H., Zheng, S., Cui, L., Li, D., . . Wang, L. (2005). Autonomy- vs. connectedness-oriented parenting behaviours in Chinese and Canadian mothers. International Journal of Behavioral Development, 29, 489-495. doi:10.1177/01650250500147063

Liu, W. T. (1986). Culture and social support. Research on Aging, 8, 57-83. doi:10.1177/0164027586008001004

Liu, Y., \& Feng, X. (2005). Kindergarten educational reform during the past two decades in mainland China: Achievements and problems. International Journal of Early Years Education, 13, 93-99. doi:10.1080/09669760500170933

Mast, V. A. (2002). Maternal problem-solving behaviors and their impact on collaboration in preschool dyads. Unpublished doctoral dissertation, University at Albany, New York.

National Bureau of Statistics of China. (2007). Average income of residents in Beijing. Retrieved November 2006, from www.stats.gov.cn/tjfx/

Neitzel, C., \& Stright, A. D. (2003). Mothers' scaffolding of children's problem solving: Establishing a foundation of academic self-regulatory competence. Journal of Family Psychology, 17, 147-159. doi:10.1037/0893-3200.17.1.147

Neitzel, C., \& Stright, A. D. (2004). Parenting behaviours during child problem solving: The roles of child temperament, mother education and personality, and the problem-solving context. International Journal of Behavioral Development, 28, 166-179. doi:10.1080/01650250344000370

Pang, Y., \& Richey, D. (2007). Preschool education in China and the United States: A personal perspective. Early Child Development and Care, 177, 1-13. doi:10.1080/14797580500252712

Parke, R. D. (2004). Development in the family. Annual Review of Psychology, 55, 365-399. doi:10.1146/annurev.psych.55.090902.141528

Plumert, J. M., \& Nichols-Whitehead, P. (1996). Parental scaffolding of young children's spatial communication. Developmental Psychology, 32, 523-532. doi:10.1037/0012-1649.32.3.523

Pratt, M. W., Kerig, P., Cowan, P. A., \& Cowan, C. P. (1988). Mothers and fathers teaching 3-year-olds: Authoritative parenting and adult scaffolding of young children's learning. Developmental Psychology, 24, 832-839. doi:10.1037/0012-1649.24.6.832 
Rao, N., McHale, J. P., \& Pearson, E. (2003). Links between socialization goals and child-rearing practices in Chinese and Indian mothers. Infant and Child Development, 12, 475-492. doi:10.1002/icd.341.

Renshaw, P. D., \& Gardner, R. (1990). Process versus product task interpretation and parental teaching practice. International Journal of Behavioral Development, 13, 489-505. doi:10.1177/016502549001300406

Rogoff, B. (1990). Apprenticeship in thinking. New York: Oxford University Press.

Stevenson, H. W., \& Stigler, J. W. (1992). The learning gap: Why our schools are failing and what we can learn from Japanese and Chinese education. New York: Simon \& Schuster.

Tabachnick, B. G., \& Fidell, L. S. (2007). Using multivariate statistics. Boston: Pearson Education.

Vygotsky, L. S. (1978). Mind in society: The development of higher psychological processes. Cambridge, MA: Harvard University Press.

Wertsch, J. V., Minick, N., \& Arns, F. J. (1984). The creation of context in joint problem-solving. In B. Rogoff \& J. Lave (Eds.), Everyday cognition: Its development in social context (pp. 151-171). Cambridge, MA: Harvard University Press.

Wood, D., Bruner, J. S., \& Ross, G. (1976). The role of tutoring in problem solving. Journal of Child Psychology and Psychiatry, 17, 89-100. doi:10.1111/j.1469-7610.1976.tb00381.x

Wood, D., \& Middleton, D. (1975). A study of assisted problem-solving. British Journal of Psychology, 66, 181-191.

Xu, Y., Farver, J. A. M., Zhang, Z., Zeng, Q., Yu, L., \& Cai, B. (2005). Mainland Chinese parenting styles and parent-child interaction. International Journal of Behavioral Development, 29, 524-531. doi:10.1177/01650250500147121

Zegiob, L., \& Forehand, R. (1975). Maternal interactive behaviors as a function of race, socioeconomic status, and sex of the child. Child Development, 46, 564-568. doi:10.1111/1467-8624.ep12188343 
Reproduced with permission of the copyright owner. Further reproduction prohibited without permission. 